\title{
Systems Methodology for Strategic Decision-making in Complex Healthcare System
}

\author{
TADEJA JERE JAKULIN
}

\begin{abstract}
Systems methodology as a support for strategic decisionmaking will be discussed in the paper. A society will be presented as a complex system, which is comprised of many smaller, complex systems as its component parts. The healthcare system is one of them. The support to the strategic decision-making in a healthcare system will be shown through systems thinking and systems modelling. We will develop models of a healthcare system in frame of a systems dynamics; a qualitative causal loop diagram (CLD), which helps us to discuss the challenges categorically and a quantitative model, which is a simulation model. Both models illustrate the discussed methodology.
\end{abstract}

Keywords: • systems methodology $\bullet$ healthcare system $\bullet$ strategic decision-making $\bullet$ systems thinking $\bullet$ modelling

CoRRESPONDENCE AdDress: Tadeja Jere Jakulin, Ph.D., Associate Professor, University of Primorska, Faculty of Tourism Studies - Turistica, Obala 11a, 6320 Portorož, Slovenia, e-mail: tadeja.jerejakulin@upr.si. 
Systems approach became a necessity in contemporary life, which we see as a modern complex system comprised of a variety of other systems and their elements. Reductionism was the driving force behind much of the twentieth century's scientific research (Barabasi, 2014). In the paper, we will discuss the opposite of reductionism; namely, systems view upon the society and healthcare as a complex system. Thinking in systems and systems approach presents a new way of looking upon contemporary complex society. Systems thinking is also called strategic thinking since it can anticipate the future by using feedback loop information and holistic point of view. It is a new methodology which can optimally manage challenges that require more than just a superficial touch to make a move from low optimum to optimal strategic decision-making. Healthcare as an element of the society will be discussed as a system, which strives for optimal decision-making. We will present the terms and methods of systems methodology: complexity, systems thinking as the opposite to analytic thinking, and systems modelling. The difference between analytic (conventional and systems (strategic) thinking lies in thinking "in the box" or "out of the box". Analytic thinking explains independent factors addressed in isolation, each of which can be pushed to a point, beyond which they have reached maximum capacity, and further gains are achieved only at expense of another element. Systems thinking, on the other hand, is interdependent thinking, where elements are interconnected, such that changes to one of the elements impact all other elements (Gharajedaghi, 2006). Systems approach as such has been accepted within natural sciences since Ludwig von Bertalanffy published his manifesto of General System Theory ${ }^{1}$ (Bertalanffy, 1952) and Norbert Wiener published his work on Cybernetics (Wiener, 1948). The systems theory is, due to its integrative nature, an important tool for achieving precision in the nonphysical areas of science. Before achieving general acceptance, the theory of systems was treated an amorphous, semi- metaphysical concept. The intention of general systems theory and cybernetics is the "ontology" of action, which is revealed by feedback information. Its goal is to find a method to predict the consequences of any given decision-making action. Industrial engineering recognised the theory when Forrester published his work, Industrial Dynamics (Forrester, 1961) and social sciences rediscovered it with Senge's work on learning organisation entitled The Fifth Discipline (Senge, 2006). Systems theory leads to an important goal contemporary modern science should reach: the goal of unity, where the various scientific disciplines act in unison and complement each other. Thus, the systems approach was developed over time. The systems approach represents a methodology for complex research, theory and cybernetics, and the aforementioned disciplines each play an important role in the various fields of scientific research. In the paper, we will present the healthcare system as a complex system, which needs systems models to be understood in a holistic way. Thus we will build two models. The first is a qualitative graph showing the interdependency among the society at large, the healthcare system and other subsystems. This model is called the CLD 
model or the causal loop diagram. It is a verbal description of influences among the healthcare system within society and other interconnected subsystems. The simulation model will naturally follow the CLD. It will represent a model in a frame of system dynamics as an illustration of the discussed methodology. Taken together, these models will demonstrate the effectiveness of a system dynamics methodology.

We described a so-called "soft system phenomenon", where people through their actions, knowledge and characters represent a complex system of a society. As we reach a certain level of complexity, we must search for an optimal methodology to sort out and make sense of these complexities. These optimal methodologies include systems dynamics, systems thinking and systems modelling. Therefore, the anticipated system is much closer to describing the essence of complex systems behaviour. However, the influence of the observer in the process of modelling the complex system is of primary importance. To date, however, this problem has not been sufficiently considered in the literature. This article discusses the method of describing and modelling the complex healthcare system from the systems and decision-making point of view. The systems methodology is an experimental confirmation of those hypotheses, which comprise the approach and modelling theory that can survive the most rigorous testing.

\section{Complexity and Healthcare System}

The word "system" denotes a "whole" consisting of multiple "parts" and was the axiom for ancient philosophers (Kljajić \& Jere Lazanski, 2001). When we further explore the notion of complex systems, we must start with living organisms, which form the foundation for researching different areas of complexity. Living systems described by Miller (Miller, 1978) represent comparative analogy of the structure, functioning and processing the energy and information among different living phaenomena. A system is considered complex if its parts interact in a nonlinear manner. However, simple cause and effect relationships among the elements rarely exist. Instead, a very small amount of stimulus may cause either unpredictably large effects or no effect at all (Baggio, 2008). There are similarities among the living organism, organs and organisations. These are so-called "soft" or "organisational systems", where the organisation presents a voluntary association of purposeful members who manifest a choice of both ends and means. The purpose of the organisation is not only to advance the goals of its members but also those of the environment at large. In other words, such an organization is not a one-time design, but rather an ongoing evolving whole.

The members of a sociocultural organisation are bound together by one or more common objectives and collectively acceptable ways of pursuing them. The members share values that are embedded in their culture. Culture is the cement that integrates multiple parts into a cohesive whole. Since the parts have a major influence on the organization as a whole, consensus is essential to the alignment of 
a multi-minded system (Gharajedaghi, 2006).The organization's behaviour, however, is not always predictable. We can predict behaviour when we work with hard or technical systems such as airplanes, cars, computers or engines which are tested extensively before put to actual use. Living systems are viewed as selforganising networks whose components are all interconnected and interdependent. This thought was expressed throughout the history of philosophy and science (Capra \& Luisi, 2014). We can say the same for a society as a system, which we refer to as a "societal system" and a "soft system," since human beings play the most important decision-making roles in it. Complex systems are also "hard" or "technical systems", which are comprised of many components and evolutionary systems (consciousness), which evolve through time (Banathy, 2000). Typical states of complex systems are "nestings". Let us explain that. A system which is a part (i.e., a component) of a larger one can be at the same time a system in and of itself and a component in a separate, larger system. To provide a real life example to illustrate this concept, a healthcare system is a complex system. It is a part of a society known as a suprasystem. But the healthcare system is then comprised or made up of numerous smaller subsystems such as healthcare centers, hospitals and spas. One of the recent definitions of a complex system was generated by Sayama, who wrote that complex systems are networks created from many components that interact in a non-linear way. They may, for example, evolve through selforganisation such that they are neither completely regular nor completely random (Sayama 2015). Complex systems have large numbers of different interacting elements and interactions with the environment and, consequently, their collective behaviour is not merely the sum of their individual behaviors. Normally, their interaction and evolution rules are not linear. Accordingly, even small perturbances can create disproportionately large cascading effects. Complex systems are usually intuitively understood as a phenomenon consisting of a large number of elements organised in a multi-level hierarchical structure where elements themselves could represent systems (Mesarović \& Takahara, 1989). They are robust, self-organising, adaptive, and highly sensitive to initial conditions. Complex systems interact with one another and with the environment at different levels (Mobus \& Kalton 2015). Healthcare is a complex system and a part of larger system, known as a society. The description of the system depends on the specific goal and point of view of the researcher. The word "complex" is used only to point out the fact that the problem treated here cannot be expressed only in hard (quantitative) terms and that most relevant values are qualitative. With a conception of complex systems we also present a system within which a complexity of interaction among system elements plays a main role. These elements are systems themselves and for this reason the behaviour of a system as a whole cannot easily be predicted. It is the system of systems, which exchange energy and information with their environment while in transit, inflected by internal and external influences. Organisational systems among the systems of system are complex because of the existing relations and nesting of its subsystems. This idea is represented on Figure 1. 
Figure 1. Complex Healthcare System "Nesting”

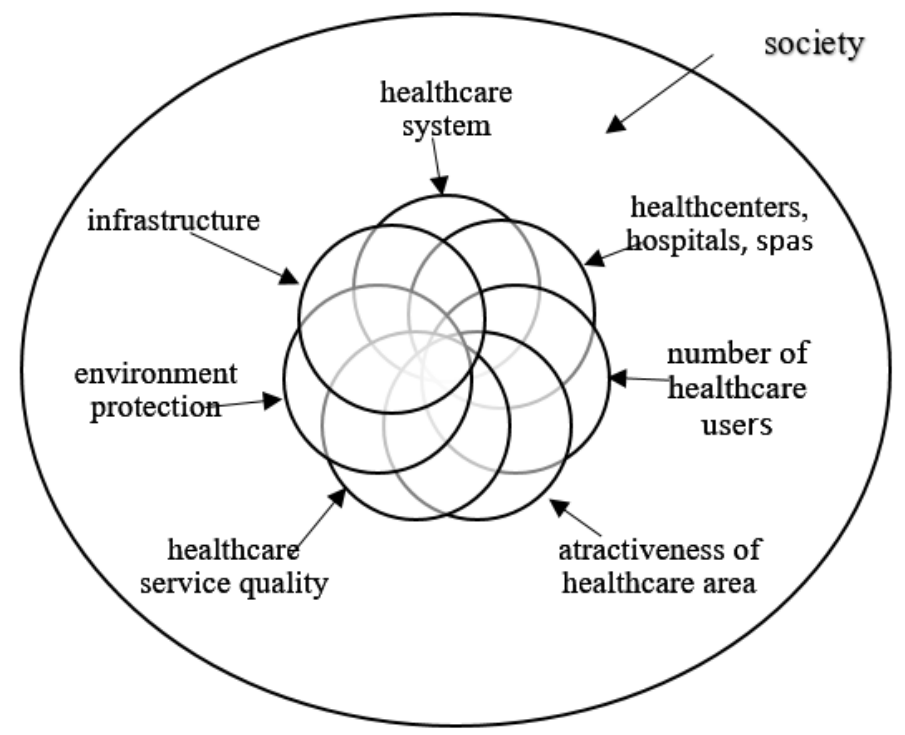

When reflecting on decision-making in the area of complex systems such as a healthcare system, a viable solution is to think systemically or to use systems thinking where feedback and feed-forward information is available. Other solutions include creating a model of natural thinking (Meadows, 2008) or thinking in cycles. Systems thinking is a conceptual framework, a body of knowledge and tools that has been developed over the past fifty years, to make the full patterns clearer, and to help us see how to change them effectively. Figure 1 shows how some healthcare systems and healthcare connected systems " "nest in a society", which represent their bigger system. This means that "systems" represent subsystems at the same time as they represent systems as wholes. The interdependency and relationships among the individual entities of these subsystems are far more important than independent systems. This is especially true between the subsystems of healthcare, infrastructure, education, healthcare institutions, and users of healthcare services, all of which influence each other. These elements are systems themselves, and for this reason, the behaviour of a system as a whole can hardly be predicted. They exchange energy and information with their environment while in transit, inflected by internal and external influences (Jere Lazanski \& Kljajić, 2006). The challenges of strategic decision-making arise with a number of systems, which nest in a bigger system. If we map the healthcare system to the national or international destination, we reach a global level of a system, which encompasses a wide variety of people, partners, branches and institutions. Those in turn also create yet another complex system with all interconnections, interdependency, and nesting in each other (dependent on a size of a subsystem). 
The healthcare system is a complex system, which evolves through the altering of relationships among its various participants as well as through its interactions with the environment within natural society. Learning and experience through decisionmaking provides development and growth that are observed through evolution. Evolution of society and experiences as part of the past and the anticipation of the future cause these systems to grow and develop with the environment as a restricting factor. In other words, the systems are dynamic and not static. A changing, everevolving society is at the junction between many subsystems in the economy and other influential sectors. As is the case with the larger economy, the healthcare system, as a smaller sub-component, itself necessarily faces many issues of uncertainty, imponderables of measurement, errors or missing data, different spatial and temporal scales and stochastic behaviour (Jere Lazanski, 2006). These details are typical for a complex system with a huge quantity of data to manipulate different spatial and temporal scales (e.g., from seconds to years, from local to global). A reasonable balance both in local and global socio-economies may lead to favourable mutual reinforcements between and among diverse cultures, social value systems, economic systems and environmental systems for the general well-being of reasonably decent humans at large (Hiwaki, 2017). Society and also healthcare systems have the same structural properties as those of a complex system - local interactions, non-linearity, feedback and openness (difficult-to-find boundaries). A complex system's behavioural properties include emergence, self-organisation and adaptiveness. Baggio (2008) and Cilliers (1998) define the symptoms of a complex system according to how these authors approach complexity. Non-determinism states that it is impossible to precisely anticipate a complex (adaptive) system's behaviour because this depends strongly on the initial conditions and appears to be extremely sensitive; the only predictions that can be made are probabilistic (Baggio, 2008). Positive and negative feedback loops influence the overall behaviour of the system. Distributed nature represents a system where many properties and functions cannot be exactly localised (Baggio, 2008). Next, the system evolves, increasing its complexity up to the next self-organisation process. One effect of such a characteristic is the capability to show a significant degree of robustness to external (or internal) shocks. At the critical points of instability, the system will reorganise itself through feedback mechanisms. The self-similarity is evidence of possible internal complex dynamics of a system. The system considered will look like itself on a different scale if reduced or magnified suitably. The last symptom of complexity is limited decomposability, indicating the impossibility of studying the properties of a dynamic structure by breaking it down into functionally stable parts. Its permanent interaction with the environment and its properties of selforganisation allow it to functionally restructure itself. Only a "whole system" approach can explain complex systems, which are adaptive with their characteristics and behaviours (Jere Jakulin, 2017). 


\section{$3 \quad$ Analytic and Systems Approach to Healthcare within Society}

Healthcare as a system is interdependent and interconnected to other subsystems of the society such as education, environment, national health programs, healthcare users, infrastructure investments, quality of healthcare services, and attractiveness of the area. To manage one or many subsystems, or a suprasystem, requires a methodology, which is optimal for decision-making and leading complex systems. Systems approach is shown as a frame, which supplements analytical approach as a whole. A whole or a system is represented by the feedback structure and the subsystem of environment, which influences the vision achieving process. The analytical (conventional) approach bases the analysis on a three step thought process.

Figure 2. Analytical-three step thought process

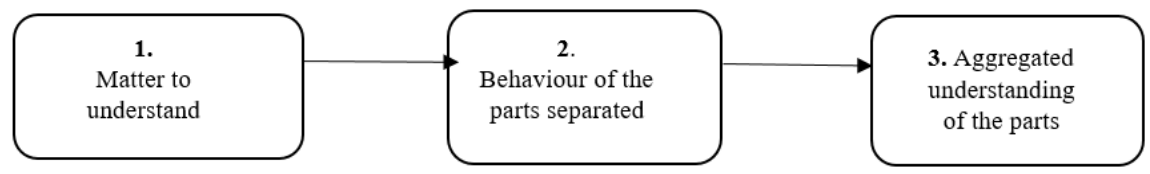

Figure 2 shows the analytical - three step thought process. This process takes apart or disassembles that which it seeks to understand; it then attempts to explain the behaviour of the component or individual parts taken separately; and finally, it tries to understand the component parts as an aggregate in order to arrive at an explanation of the whole.

In juxtaposition to the analytical approach, systems approach uses a different process. Systems approach puts the system in the context of the larger environment of which it is only a part and studies the role it plays in the larger whole. The parts are no longer the primary focus. The parts are essential, but what is more important is the interrelationship between the parts as they work together to fulfil the purpose of the whole system. Systems approach is optimal for understanding interdependency, which requires a way of thinking different from analysis; it requires systems thinking.

Figure 3: Systems- five step thought process

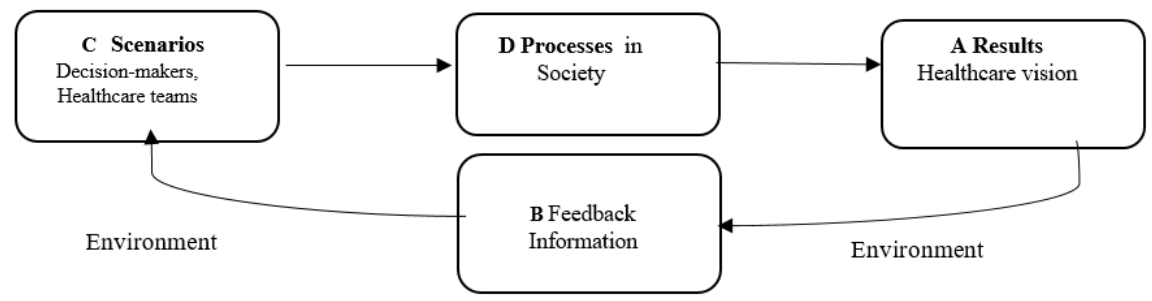


Explanation of Figure 3 starts at A: the outputs or vision of the optimal healthcare definitions and strategical documents. The group of strategic decision-makers and experts ask, as initial matters, questions about the influence of a vision that results in optimal healthcare strategical documents (outputs, A) to the environment (Eother people, nature, society), and then uses feedback information (B - what will the vision of defined strategical documents bring to the (E) and asks the following additional questions: (1) What the vision (A, outputs) will bring to the environment (E); (2) What the current situation is (C, inputs, ideas, teams, co-creation) for achieving the (A); and, (3) How they can help in the process (B) either with help or without any worries if they cannot influence the process. In order to avoid the trap of the simplicity of systems thinking, it is important to build a general model of strategic decision-making in which the decision-makers try to implement the optimal systems solutions. The most important aspect of this is the strategic vision of a society and healthcare development and systems' environment influence prediction. We can describe society with a general model, which is an idealised and simplified image of a real situation or phenomenon and which contains only the most important quantities and their functional dependencies. This model is an attempt to identify the key variables in a situation and the relationship that exists among them (Kljajić, 1998). In Figure 4 we define a general model of a goaloriented system with a pair $(P, D)$. $P$ represents managing processes in society as a goal oriented system, $\boldsymbol{D}$ represents a managing subsystem. Loop $P \rightarrow Y \rightarrow D \rightarrow U \rightarrow P$ represents feedback information, which functions on the cause consequence principle; therefore, we can call it reactive control. For small perturbations such control is satisfied. For decision making in societal system, information from the environment is necessary. Chain $X \rightarrow D \rightarrow U \rightarrow P$ provides feed forward information, which represents the anticipation of the future state of the environment. This is an important part of the strategy of goal-oriented systems.

Figure 4. General model of society as goal oriented system

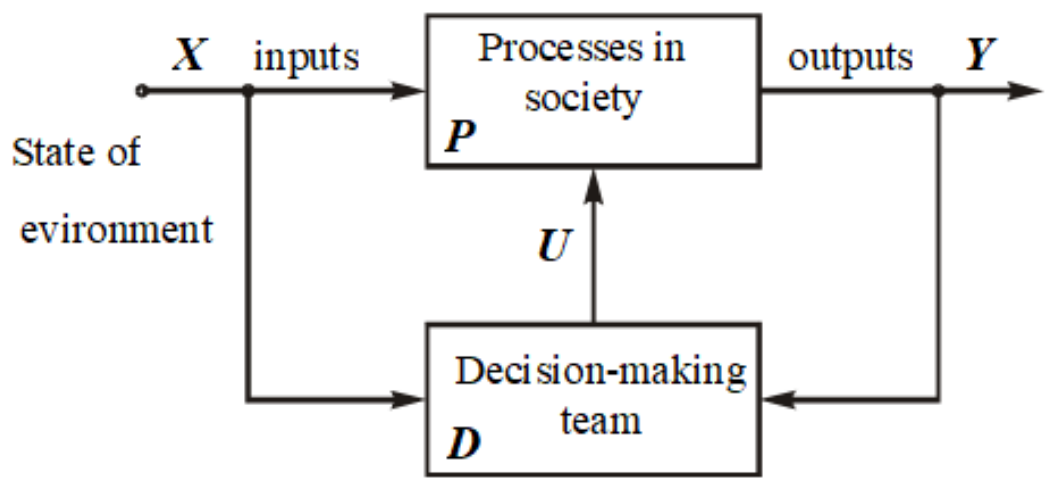


The decision-making team consists of those experts, decision-makers and people who create goals and who shoulder the primary responsibility for the development of society and it's defined subsystems: healthcare, quality of services, healthcare users and education. The achievement of optimal goals and functioning of the subsystems depends on the decision-making team's knowledge, systems consciousness, inter-relationships, along with the organisation of the technical and natural parts of the subsystem. If the decision-making team is strategically equiped, e.g. it has systems approach knowledge and systems thinking awareness, then the decisions become optimal for the supra-system (society) as well as for the subsystems (healthcare system).

\section{$4 \quad$ Methods within Systems Methodology}

As we discussed above, we find systems thinking, systems modelling and simulation as preferred methods for conducting complex systems research within systems methodology. These methods serve to better explain the world from the point of view of a "system" or a "whole". In simplistic, societal terms, this methodology might best be summed up using the expressions "The big picture view" or "Thinking out of the box". Systems methods demonstrate the object of the observation as a whole, integrated from its elements, parts or subsystems, which are tightly interconnected, interdependent, and influence each other while being parts of a whole and thus parts of the environment. The main concept of systems thinking lies in the research of system's elements interactions and their co-dependency as well as interdependency and interactions with the environment. According to Sterman (2000), people and subjects within a system react through the phenomenon of feed-back loop, where a change of one variable interacts with time thus delaying other variables. These in turn influence source variables. One of the world's leading physicists and systems thinkers, Fritjof Capra, describes system thinking in The Web of Life in the following terms: "Systems thinking shows a broader perspective, which is connected to events, patterns and finally to the structure. Patterns are trends, or changes in events over time. Whenever we see a pattern of events we get closer to grasping the systemic structure driving that pattern". (Capra 1997). For example, a General Practitioner will always give a medicine to an older person who regularly comes to his practice without examining her, or whenever there would be strong pain,. Structure always gives answers to the questions "why is this pattern happening" or "what's causing this event." Thinking at the structural level means thinking in terms of causal connections. Analysis and thinking at the structural level hold the keys to lasting, high-levered change. Actions taken at this level are creative, because they help shape the optimal future. Our ability to positively influence future events increases as we move away from event-level analysis towards pattern level and structural level thinking (Anderson \& Johnson, 1997). On the other hand, as discussed next, sometimes the most prudent action we can take must remain focused on the present, at the event level. This would be the case, for example, in reacting quickly when a person has a heart attack. 
T. Jere Jakulin: Systems Methodology for Strategic Decision-making in Complex Healthcare System

Figure 5: Levels of Understanding (adapted after: Anderson \& Johnson, 1997)

\begin{tabular}{|c|c|c|c|c|}
\hline & $\begin{array}{l}\text { Action } \\
\text { Mode }\end{array}$ & Time orientation & $\begin{array}{l}\text { Way of } \\
\text { perceiving }\end{array}$ & $\begin{array}{l}\text { Questions } \\
\text { you would } \\
\text { ask }\end{array}$ \\
\hline Events & React! & Present & $\begin{array}{l}\text { Witness } \\
\text { event }\end{array}$ & $\begin{array}{l}\text { What's the } \\
\text { fastest way } \\
\text { to react to } \\
\text { this event } \\
\text { now? }\end{array}$ \\
\hline Patterns & Adapt! & $\downarrow$ & $\begin{array}{l}\text { Measure or } \\
\text { track } \\
\text { patterns of } \\
\text { events }\end{array}$ & $\begin{array}{l}\text { What kind } \\
\text { of trends } \\
\text { or patterns } \\
\text { of events } \\
\text { seem to be } \\
\text { recurring? }\end{array}$ \\
\hline Structure & $\begin{array}{l}\text { Create } \\
\text { change! }\end{array}$ & Future & $\begin{array}{l}\text { Causal } \\
\text { loop } \\
\text { diagrams } \\
\text { and other } \\
\text { system } \\
\text { thinking } \\
\text { tools }\end{array}$ & $\begin{array}{l}\text { What } \\
\text { structures } \\
\text { are in the } \\
\text { place that } \\
\text { is causing } \\
\text { these } \\
\text { patterns? }\end{array}$ \\
\hline
\end{tabular}

Figure 5 summarizes the core of systems thinking, which is characterized by the three levels of understanding: reaction to an event; adaptation of patterns; and, creating change going to the structure. Focusing only on the first level - reaction to the event - to the exclusion of the other elements, would be short-sighted. Level one analysis considers only the proverbial "tip of the iceberg." Systems thinking people explore deeper, considering all three levels. They dig below the surface; they are not satisfied with superficial thinking. To continue with the "tip of the iceberg" analogy, strategy efforts that consider only the first level are likely to fail or sink miserably. Successful strategy efforts, on the other hand, have the hallmark of taking into account as well the "invisible information below the surface." According to Haines (Haines, 2007), 87\% of an iceberg is below the waterline. Healthcare strategy makers must take into account and analyze the two levels below the surface as their failure to do so most likely will sink strategy efforts. An optimal strategy, which causes a change for the better, depends on good processes and structures (Jere Lazanski \& Golob, 2013). Processes and structures can be recognised with a scheme of systems simulation, which is needed in showing the dynamics of a researched system. It tries to achieve the understanding of basic systems structure and its behaviour through time. The final aim of the systems dynamics method is the development of a simulation model, which on the computer quantitatively presents 
systems behaviour utilizing different assumptions. In the literature, the methodology is known as "what if "analysis, or more precisely, system's behaviour with different scenarios. The simulation scheme is presented in figure 6 .

Figure 6. Systems simulation methodology in a healthcare system (adapted from Kljajić, 1994)

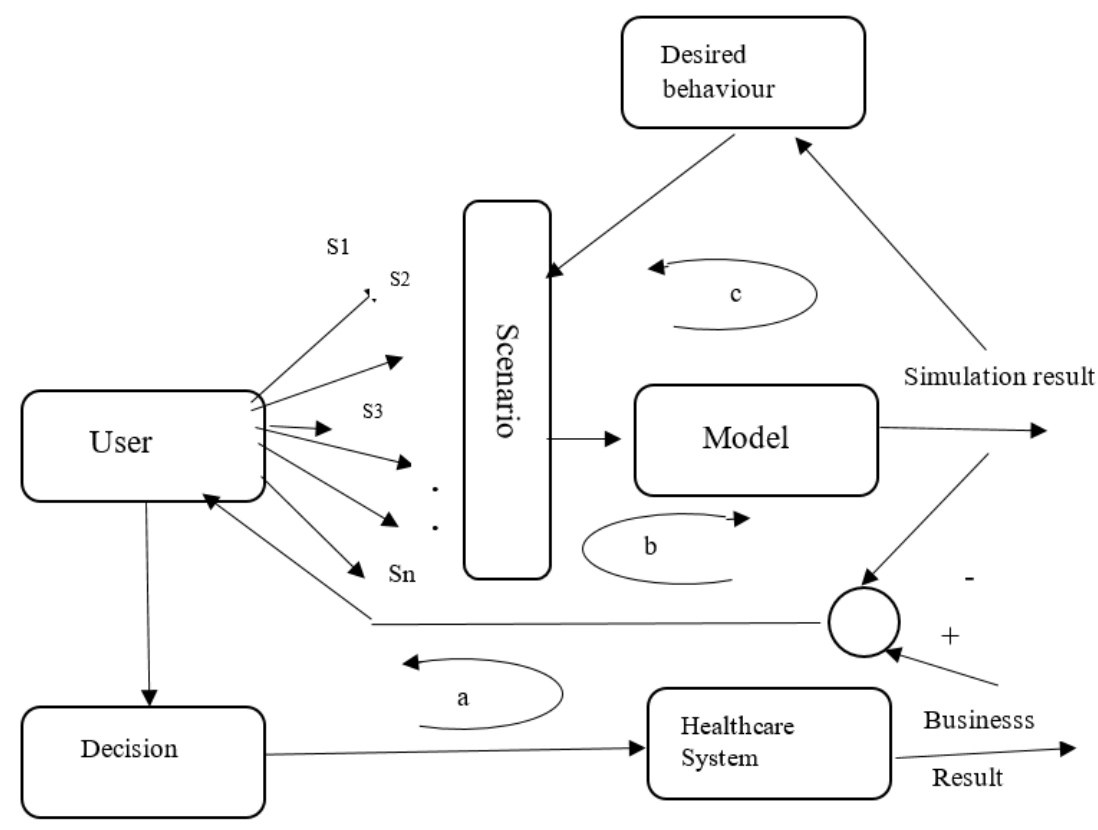

Figure 6 represents the systems simulation methodology utilized in a general business system. We have adapted it to the healthcare system. The three basic circles $\mathbf{a}, \mathbf{b}$ and $\mathbf{c}$ and feed-back loops show the interactions among the user, simulation model and scenario in a problem- solving phase. Feedback loop a presents results, which are the consequences of previous decisions. It is a part of the systems history and a part of the experiences of the problem owner. The $\mathbf{b}$ circle presents pragmatic validation of the model. With a comparison of the future information about an impact of the chosen scenario onto the systems behaviour, we are able to validate the model and improve it. This comparison also enables learning from a posterior assumptions. Intellectual circle c (anticipative circle) enables us to see and analyse the future information and is important for systems strategy. The most sensitive part of this circle is methodology of systems simulation, which enables testing the system's model. 


\section{$5 \quad$ Building a (CLD) causal loop diagram and (SD) simulation models of healthcare systems}

When we discuss a healthcare system as a complex system, we think of interconnected elements, which influence each other: soft (people involved in healthcare), hard (technical, law) and evolutionary (consciousness) elements of the system (Jere Lazanski, 2010). One of the most crucial steps in the engineering process is to select a structure for the system to be designed or, similarly, to analyse the structural considerations of the behaviour and operation of a system (Mesarovic, 1967). The number of works dedicated to the different models and methodologies devoted to social, economic and natural areas is very high. These include: System Dynamics (Forrester, 1961), System Thinking (Senge, 1994), Autopoietic System (Maturana, 1998), Living Systems (Miller, 1978), Viable Systems (Beer, 1959), Anticipatory Systems (Rosen, 1985) as well as others. Some relevant paradigms to system analysis were described in (Rosenhead, 1989, Mulej 1992). Systems modelling requires decision-making provided by a group of experts, who cover inter-disciplinary areas of healthcare. This is shown in figure 7, which presents the healthcare expert group as a part of the healthcare legislative process, where modelling and ideas about strategical documents and regulation determination represent a knowledge-capturing process in the form of the structure and behaviour of the model evaluation functions relating to the given situation. Simulated and actual performances of the system are compared in order to adapt the strategy according to changes in the environment.

Figure 7. The principle scheme of simulation methodology for decision-making support

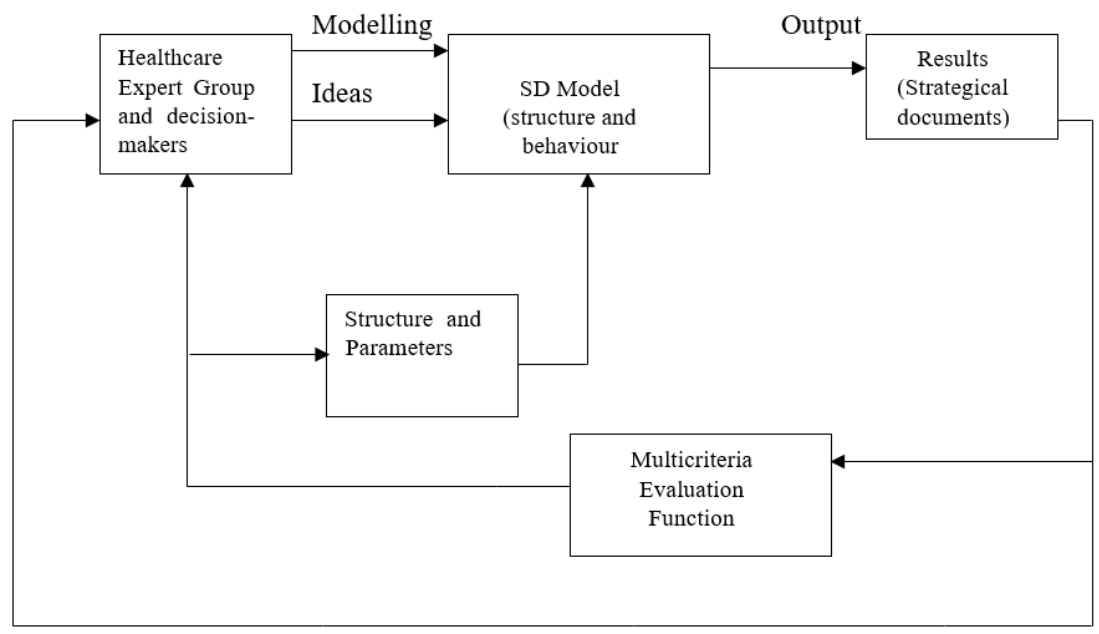


Figure 7 shows the principle scheme of the decision-making simulation methodology. Once the model is defined and validated, experimentation with different ideas and scenarios is possible. The healthcare expert group determines the set of different ideas, which represents possible future activities in the real system. The results gathered as the output of the model are evaluated with the multicriterial evaluation function. At this stage, many different multi-criterial evaluation methods may be used from weighted average (Vincke, 1992) to the Analytical Hierarchy Process (AHP), (Saaty, 2012) and Expert systems (ES) (Rajkovič \& Bohanec, 1991). Information feedback provides the expert group with the possibility of creatively determining a new set of ideas on strategical documents and multi-criteria evaluation functions. The systems thinking solving method with simulation model follows standard steps: state analysis, development of causal-loop diagrams, writing of the model's equations and model implementation. Particular scenarios that form and determine a tourist market in a certain environment are tested on a simulation system. A simulator is connected to the GSS (Group Support System). The participants using GSS work directly with the system simulator. A system simulator is connected to a database, which is necessary for simulation model activation. Simulation results are evaluated both with the group decisionmaking support system and with expert systems. In all of this, the understanding of the system increases. With the described model, the experimental loop on a simulation model can be finished with the help of the system simulator and scenario ranking. The elements of the decision-making support system are Powersim, a tool for the construction and use of a simulator; Ventana Group Systems, the Ventana group working support system; DEX, a shell of an expert system expert; and Expert Choice, evaluation with the AHP method. Since the work with the group decisionmaking tool is anonymous, this tool raises creative thinking, which in turn enables a greater flow of ideas and reduces unwanted influences. The participants become more relaxed, since no one will be able to ascertain where the ideas originated, and thus creativity is enhanced; this simply would not be the case using the more "classical" ways of working. The work time decreases and the efficiency of participants increases (Jere Jakulin, 2017). The final result is better, as the decision becomes a group decision in which conflict between polarised groups is minimised and a consensus is achieved for the development of further actions. By receiving all important information about which subsystems influences the researched system, we can build an influential qualitative diagram of interconnectedness and codependency among the observed subsystems. Qualitative models are "the language" of professionals, who describe complex co-dependencies (Senge, 2006). For the illustration of this method we will build the causal loop diagram (CLD). Figure 8 presents a CLD of a healthcare system with the society as the bigger system. We assume that a healthcare system is connected to many subsystems within a society such as national healthcare program, infrastructure, environment, education, number of people-users of healthcare services, healthcare centers, hospitals, spas, and healthcare service. 
Figure 8: CLD of a healthcare system

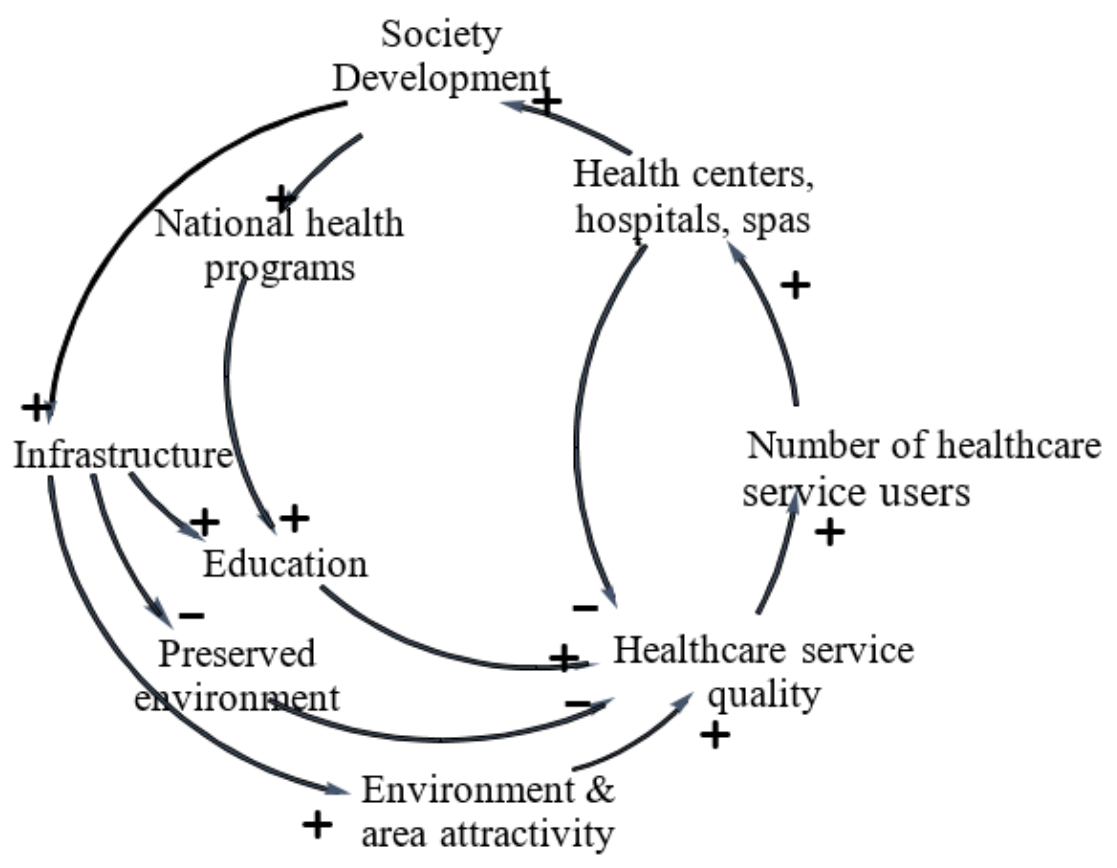

Fig. 8 shows feedback circles and interactions among the elements. The arrows between the elements show the direction of the influence. The sign at the arrows shows the trend of the change. A plus sign (+) denotes: if the value of the first variable increases, the value of the second variable also increases. A minus sign (-) denotes: if the value of the first variable increases, the value of the second variable decreases. The society has positive influence onto infrastructure (+); building infrastructure increases atractivity of the environment and area $(+)$; the environment and area increase quality of healthcare services $(+)$; these positive attributes influence the number of healthcare services users $(+)$; which in turn leads to an increase in the health centers, hospitals, spas $(+)$; which in turn leads to an increase in overall society development. This we call a reinforcement circle. The circles with (-) signs represent the circles of regulation. An increased number of healthcare services users $(+)$ negatively influences $(-)$ the quality of healthcare services. We can emphasize that new infrastructure negatively influences the environment preservation (-), which also causes the decrease of service quality (-). Society development increases $(+)$ national health programs, which positively influence education (+) and consequently increase healthcare services. Positive feedback circles represent growth or development. Every decrease in the cirle is followed by the a decline in growth. These models are important for defining the development of the system as a whole. Negative or regulation circles always illustrate the limiting 
factors of a development, which, while they cannot be avoided, yet can be controlled by the society. The diagram is abstract enough to enable a qualitative analysis of the system's dynamics and feedback circles signs. This is called a structure analysis of the system's model. This step is very important and with this technique we can, in a rational and reasoned way, define every phenomenon (Jere Jakulin, 2016).

The next diagram, shown in Figure 9, shows the structure of a healthcare macromodel, which is a so-called quantitative simulation model in frame of systems dynamics (SD). From this diagram, one can derive the dynamic equations, which are necessary for a computer simulation. The construction of the SD model creates an effective learning atmosphere in which new insights on the strategic problems are gained (Vennix, 1996). The parameters are not quantitatively evaluated, since there is much work to do with analysing the details of a model. This is only an answer and a presentation of possible results.

Figure 9: Simulation model of healthcare (adapted from Jere Lazanski, 2010)

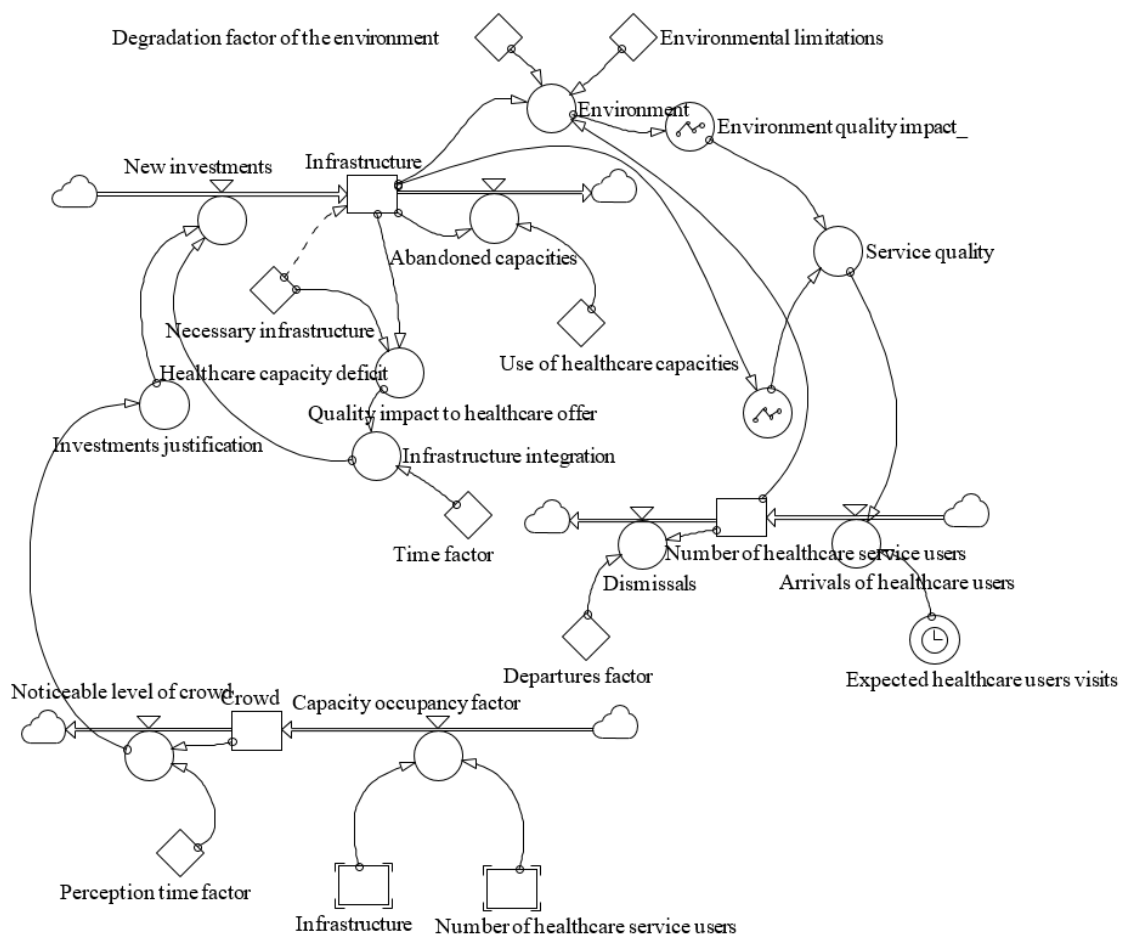

A simulation model of a healthcare system is presented in figure 9. The number of heath service users depends on their arrivals and departures. Service quality depends 
on the numbers of its user's environment preservation and capacity occupancy factor.

Profit in the healthcare system (beauty healthcare services, wellness services in the system of healthcare, luxury services) causes higher investments to the infrastructure, which has a negative impact on the environment and the number of users. Negative influences can be noticed by, for example, crowds of people in waiting rooms. Quantitative models, which are actually simulation models, always follow causal loop diagrams. The difference lies in a number of parameters in data needed for a simulation.

\section{Conclusions}

In the paper we discussed the application of systems methodology to a complex healthcare system. We followed methods of systems thinking, modelling and simulation. We presented:

- Generality and definitions of systems thinking, modelling and simulation in frame of system dynamics.

- Context dependent modelling, which is in dependency of the healthcare problem and experiences of its participants.

- A way of transmission from verbal problem description to causal loop diagram (CLD), which enables a categorical debate of a problem.

- As an illustration of a methodology, we built a simulation model of healthcare as a complex system.

When we modelled a causal loop diagram of the healthcare system and its development, we treated a health system as an object, whose relationship to a connected system explained a healthcare model. We used a dynamics model and a concept of hypothesis testing, which enabled new opportunities for solving virtual problems in complex systems modelling. We showed the equivalence of the models whose differences or similarities can be judged only in the context of a problem and the aims of researchers. It appears that systems methodology and the dynamics methods are appropriate means for modelling concrete complex questions, which appear with strategic decision-making. Systems thinking and complex system modelling in a frame of dynamics deserves stronger attention in the future. They are an experimental confirmation of those hypotheses, which comprise the approach and modelling theory. When we approach a complex problem with linear or analytical thinking, we fail. It appears impossible to solve complex problems without a big picture in mind. Feedback loops bring us to the systems perspective or the so-called big-picture point of view. In the case of a healthcare system, systems educated and oriented decision makers bring creativity to teams. The systems approach becomes a creative drive for healthcare system(s) and society. 
MEDICINE, LAW \& SOCIETY

\section{Notes}

${ }^{1}$ Ludwig von Bertalanffy, an Austrian biologist, used the term General System Theory. Throughout this paper we use the following terms: systems theory, systems thinking, systems modelling and systems dynamics, (system»s«), which is accepted as contemporary systems terminology.

\section{References}

Anderson, V. \& Johnson, L. (1997) Systems Thinking Basics:From Concepts to Causal Loops (Williston: Pegasus Communication).

Baggio, R. (2008) Symptoms of Complexity in a Tourism System, Tourism Analysis, 13(1), pp. 1-20, doi: 10.3727/108354208784548797.

Bánáthy, B. H. (2000) Guided Evolution of Society: A Systems View (Contemporary Systems Thinking) (New York: Kluwer Academics/Plenum Pulishers).

Barabasi, A. L. (2014) Linked: How Everything is Connected to Everything and What it means for Business, Science and Everyday Life (New York: Basic Books).

Beer, S. (1959) Cybernetics and Management (London: English University Press).

Bertalanffy, L. von (1952) General System Theory (New York: George Brazziler).

Capra, F. (1997) The Web of Life (New York: Anchor Books of Random House).

Capra, F. \& Luisi, P. L. (2014) The Systems View of Life:A Unifying Vision (Cambridge: Cambridge University Press).

Cilliers, P. (1998) Complexity and Postmodernism: Understanding Complex Systems (London, New York: Routledge).

Forrester, J. W. (1961) Industrial Dynamics (Boston: MIT).

Forrester, J. W. (1994) System Dynamics, Systems Thinking, and Soft OR, System Dynamics Review, 10(2/3), pp. 245-256, doi: 10.1002/sdr.4260100211.

Gharajedaghi, J. (2006) Systems Thinking-Managing Chaos and Complexity: A Platform for Designing Business Architecture (Burlington: Butterworth-Heinemann).

Haines, S. (2007) Tools for Strategic Thinking:The Simplicity of Systems Thinking (Los Angeles: Systems Thinking Press).

Hiwaki, K. (2017) A Balance Paradigm for Post-Plutocracy: Toward Sustainable Development with Integral Harmony, Systems (MDPI), 5(1), pp. 1-45, doi:10.3390/systems5010016.

Jere Jakulin, T. (2017) Systems Approach as a Creative Driving Force for a Tourism Destination, In: Királ'ová A. (ed.) Driving Tourism Through Creative Destinations and Activities (Hershey: IGI Global), doi: 10.4018/978-1-5225-2016-0

Jere Jakulin, T. (2016) Kvalitativno modeliranje kompleksnih sistemov v turizmu (Koper: Založba Univerze na Primorskem).

Jere Lazanski, T. \& Golob, A. (2013) Systems approach to life-long integral education, In: Lasker, G.E., Hiwaki, K. \& Aydin, A. (eds.) Advances in education. Volume X., Life-long integral education for a viable human future. T (IIAS - International Institute for Advanced Studies in Systems Research and Cybernetics), pp. 45-49.

Jere Lazanski, T. (2010) Sistemski pristop in modeliranje kompleksnih sistemov $=$ Systems approach and complex systems modelling, Bilten: ekonomika, organizacija, informatika $v$ zdravstvu, 26(3), pp. 86-91. (in Slovene)

Jere Lazanski, T. (2006) System dynamics models to support decision-making in tourism, In: Ovsenik, R. \& Kiereta, I. (eds). Destination Management (Frankfurt/Main: P. Lang), pp.6689. 
T. Jere Jakulin: Systems Methodology for Strategic Decision-making in Complex Healthcare System

Jere Lazanski, T. \& Kljajić, M. (2006) Systems approach to complex systems modelling with special regards to tourism, Kybernetes: the international journal of systems \& cybernetics, 35(7/8), pp. 1048-1058, doi: 10.1108/03684920610684779.

Kljajić, M. (1998) Modelling and Understanding the Complex System within Cybernetics, In: Ramaekers, M. J. (ed.) 15th International Congress on Cybernetics, Association International de Cybernetique, pp. 864-869.

Kljajić, M. (1994) Teorija sistemov (Kranj: Moderna organizacija).

Kljajić, M. \& Jere Lazanski, T. (2001) Systems Approach to Modelling a Complex System: (with special regards to inter-organisational system), In: Dubois, D. (ed.) CASYS'01, International Journal of Computing Anticipatory Systems, 13, pp. 211-225.

Maturana, H. \& Varela, F. J. (1987). The Tree of Knowledge (Boston: Shambala Publications, Inc.).

Meadows, D. (2008) Thinking in Systems: A Primer (White River Junction: Chelsea Green Publishing).

Mesarovic, M. D. \& Yasuhiko, T. (1989) Abstract Systems Theory (London, New York: Springer Verlag).

Mesarovic, M. (1967) General Systems theory and its Mathematical Foundation, In: SystenLs Science and Cybernetics IEEE (Boston, MA: Clearing House).

Miller, J. G. (1978) Living Systems (New York: McGraw-Hill Book Company).

Mobus, G. E. \& Kalton, M. C. (2015) The Principles of Systems Science (New York: Springer Verlag)

Mulej, M. (1992) Theory of Systems (Maribor: EPF).

Rajkovič, V. \& Bohanec, M. (1991) Decision Support by Knowledge Explanation, Sol, G. H \& Vecsenyi, J. (eds.) Environments for Supporting Decision Processes (North Holland: Elsevier), pp. 547-571.

Rosen, R. (1985) Anticipatory Systems (New York: Pergamon Press).

Rosenhead, J. (1989) Rational Analysis for a Problematic world (West Sussex: John Wiley).

Saaty, T. L. (2012) Decision making for Leadres:The Analytical Hierarchy Procces for Decisions in a Complex World (Pittsburgh: RWS Publications).

Sayama, H. (2015) Introduction of modelling and analysis of complex systems (New York: State University of New York).

Senge, P. (2006) The Fifth Discipline:The Art and Practice of The Learning Organization. (New York: Doubleday).

Sterman, J. D. (2000) Business Dynamics: Systems Thinking and Modelling for a Complex World (Boston: Irwin McGraw Hill).

Vennix, J. A. M. (1996) Group Model Building:Facilitating Team Learning Using System Dynamics (Chichester: John Wiley \& Sons).

Vincke, P. (1992) Multicriteria Decision-Aid (Chichester: John Wiley \& Sons).

Wiener, N. (1948) Cybernetics (New York: John Wiley \& Sons). 